\title{
OVERVOLTAGE PROTECTION FOR HIGH FREQUENCY HIGH VOLTAGE POWER TRANSFORMERS
}

\author{
Diego Teruo Mendes de Souza ${ }^{1}$, Bruno Valverde ${ }^{1}$, José Antenor Pomilio ${ }^{2}$ \\ ${ }^{1}$ Zasso Brazil, Indaiatuba - SP, Brazil \\ ${ }^{2}$ University of Campinas, Campinas - SP, Brazil \\ e-mail: diegoteruomendes@gmail.com, brnovalverde@gmail.com, antenor@fee.unicamp.br
}

\begin{abstract}
Transformers with high-voltage operation may have undesired behavior due to the effects of their parasitic elements. In power electronics applications, if the primary voltage has harmonics, transformer resonances may be excited, causing high primary currents and secondary voltage stress, compromising the device isolation. This behavior is quite dangerous if the transformer operates without load, what means, without damping, because in this situation, the secondary voltage peak can reach more than two times the expected (rated) value. To protect the high frequency high voltage transformer against this dangerous operation, the overvoltage problem in open load condition is carefully explored and explained in this paper, with the proposition of different protection strategies to mitigate its effect, depending on the transformer parasitic elements values. The different strategies are analytically explained and validated by experimental results, showing their criteria design and effectiveness for the protection of high frequency high voltage transformers through the analysis of a $1 \mathrm{kVA}, 311 \mathrm{~V}, 20 \mathrm{kHz}, 42 / 512$ ferrite core transformer, showing its dynamics working alone and with each protection strategy.
\end{abstract}

Keywords - High Frequency High Voltage Transformer, Overvoltage Protection, Parasitic Elements, Power Electronics, Resonance Excitation.

\section{INTRODUCTION}

Transformers are electrical devices of great importance in Electrical Engineering, with typical applications as measurement instruments, electrical insulation, and power transmission [1] [2]. Many aspects are considered for the correct transformer's operation, as its thermal behavior, magnetic coupling, parasitic elements, depending on the application and power transfer. Thus, for the correct design, several models and simulations are adopted [2].

Transformers used in transmission lines operate at 50 or $60 \mathrm{~Hz}$ with high voltage ratio, being heavy and bulky. The frequency increase to $\mathrm{kHz}$ or $\mathrm{MHz}$ reduces considerably the transformer weight and volume, as in high-frequency devices in switched-mode power supplies [3], used with electronic converters that produce waveforms at high frequencies [4].

There are several challenges in high frequency (HF)

Manuscript received 19/06/2019; first revision 01/08/2019; accepted for publication 25/12/2019, by recommendation of Editor Marcello Mezaroba. http://dx.doi.org/10.18618/REP.2020.1.0045 transformers design, especially in high voltage (HV) operation because, in this case, it's usual the strong manifestation of parasitics [5] [6] [7] [8] [9]. It's quite difficult getting a general procedure to design these transformers, although specific procedures have been adopted in resonant converters [11] [12] [13] [14] [15] and weed control [16], and different topologies have been explored, as star-core [12] and planar transformers [17] [18].

In some applications the load varies from short-circuit to open-load, unpredictably [16] [19] [20]. When the variation is slow, control strategies can compensate the perturbations [9] [10] [12]. However, if the variation is too fast, the protection must be guaranteed by the transformer itself, avoiding dangerous situations like overcurrents and overvoltages [21].

In [22] the overvoltage problem in the open load condition of $\mathrm{HF} \mathrm{HV}$ transformers was investigated and some approaches to avoid this effect were considered. Simulations showed the effectiveness of each procedure and they were experimentally validated only in low voltage, low power tests.

A deeper understanding of the strategies is presented in this paper, showing their effectiveness through experimental measurements in high voltage high power applications. Their working and design procedure are showed through analytical approach and waveform analyses. The strategies were developed for a situation in which the load presents a really fast variation, and so the system must react instantaneously to disturbances. Their working principle is showed in a comparative way, highlighting and relating the effectiveness with transformer parameters.

Section I gives a brief introduction, contextualizing and defining the problem; Section II describes the methodology to obtain the transformer parameters; Section III defines and simulates the protection strategies; Section IV derives analytical expressions and shows waveforms that highlight the strategies and the project criteria; Section V shows the experimental results and Section VI concludes the paper.

\section{HF HV TRANSFORMER MODEL}

Different high frequency models can illustrate the transformer operation. When the interest is the transient behavior and the propagation time is relevant, distributed parameters models can be used [23] [24], otherwise, lumped models are available [25] [26] [27].

A lumped model is showed in Figure 1. The parameters are reflected to the primary side. The windings capacitance 
$C_{p}$ represents the effect of the intrinsic capacitances among the adjacent winding turns and is mainly due to the high number of secondary turns. Other lumped models use additional capacitances and inductances [25] [26] [27]. Besides its simplicity, the lumped model in Figure 1 is adequate and precise enough to represent the transformer power transferring and instantaneous load change phenomena and so, it's adequate for power electronics application without any further complexity addition [28].

The windings resistance $R_{d}$ has a small value and can be determined with a DC source (ohmmeter). Nevertheless, in high frequency, the skin and proximity effect must be taken in consideration [29] [30]. The transformer of this work uses litz wire to minimize the skin effect [31]. The AC resistance would be almost $64 \%$ more than the DC value for the solid conductor at $20 \mathrm{kHz}$, while it is only $19.1 \%$ with the use of litz wire, about 3 times less.

The $R_{p}$ value can be estimated using an adaptation of the Steinmetz's equation [32] and has a high value. The data from the manufacturer allows estimating the losses and so, the equivalent shunt resistance.

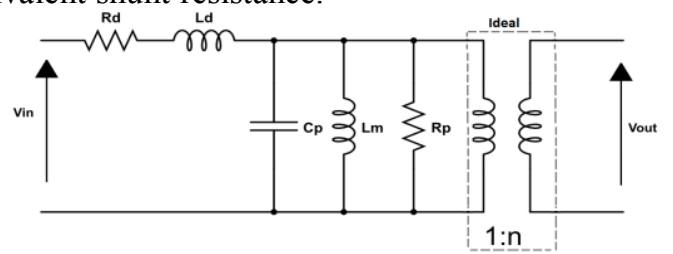

Fig. 1. Lumped model representation of the HV transformer.

Neglecting the core saturation, the remaining parameters are estimated through spectral analysis, applying a sinusoidal signal at the primary, with the secondary in open load condition. With the measurement of the primary voltage and current, the input impedance can be determined.

In low frequency range, the winding capacitance can be neglected, because of its high reactance. The resulting input impedance is the sum of the magnetizing and leakage reactances. As the magnetizing inductance is much higher than the leakage's, its approximated value is determined.

Using the same approach in the high frequency, where the capacitive reactance is so small that cancels the effect of the magnetizing inductance, the equivalent input impedance is only due to the leakage reactance. After this calculation, the magnetizing inductance is determined more precisely.

The low frequency resonance $f_{p}$ (parallel resonance) occurs between $L_{m}$ and $C_{p}$. At this point the maximum input impedance regards $R_{p}$. Nevertheless, as this essay uses a low voltage source, it's difficult to get the correct value of $R_{p}$.

Above this frequency, the input impedance presents a capacitive behavior. The high frequency resonance $f_{s}$ (series resonance) occurs between $L_{d}$ and $C_{p}$ and gives the minimum input impedance. This minimum value represents the resistance at this frequency, which, due to the skin effect, doesn't represent the resistance at lower frequencies.

The $C_{p}$ value can be calculated using both parallel and series resonances by (1) and (2) respectively, and the values must be close. The transformer's input impedance and the voltage gain are given by (3) and (4) respectively.

$$
\begin{gathered}
C_{p}=\frac{1}{\left(2 \pi f_{p}\right)^{2} L_{m}} \\
C_{p}=\frac{1}{\left(2 \pi f_{s}\right)^{2} L_{d}} \\
Z_{\text {in }}=\frac{R_{d}+s\left[L_{d}+L_{m}\left(1+\frac{R_{d}}{R_{p}}\right)\right]+s^{2} L_{m}\left(\frac{L_{d}}{R_{p}}+C_{p} R_{d}\right)+s^{3} L_{d} L_{m} C_{p}}{1+s \frac{L_{m}}{R_{p}}+s^{2} L_{m} C_{p}} \\
\frac{V_{\text {in }}}{V_{\text {out }}}=\frac{s n L_{m} R_{p}}{R_{p} R_{d}+s\left[R_{d} L_{m}+R_{p}\left(L_{d}+L_{m}\right)\right]+s^{2} L_{m}\left(L_{d}+R_{d} R_{p} C_{p}\right)+s^{3} R_{p} L_{m} L_{d} C_{p}}
\end{gathered} .
$$

\section{A. Transformer's Parameters}

The analysis uses the $1 \mathrm{kVA}, 311 \mathrm{~V}, 20 \mathrm{kHz}$ ferrite transformer showed in Figure 2. The core has a cross-section of $6.4 \mathrm{~cm}^{2}$ and maximum flux density of $0.15 \mathrm{~T}$. The primary and secondary number of turns are respectively 42 and 512 , so the voltage ratio is 12 . The secondary is divided in two equal layers, with the primary between them, improving the magnetic coupling. A signal generator feeds the primary, the secondary is open. Figure 3 shows the primary waveforms at $1 \mathrm{kHz}$.

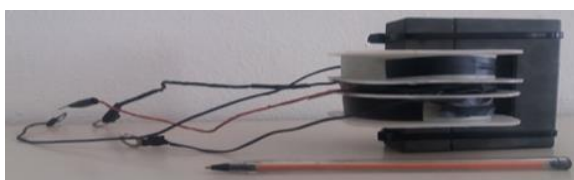

Fig. 2. HF HV transformer used in the spectral analysis performed in this section and in the experimental measurements.

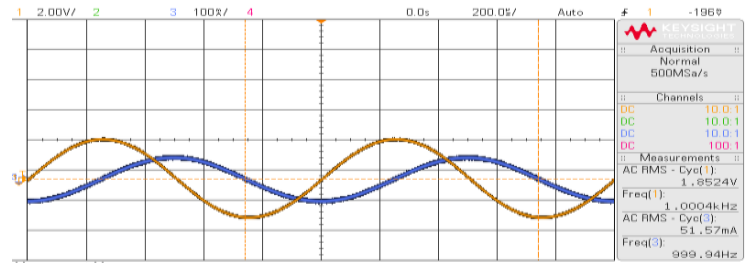

Fig. 3. Primary voltage (yellow) and current (blue) at low frequency range, used to estimate the magnetizing inductance value.

Figure 4 shows the situation at $50 \mathrm{kHz}$, the parallel resonance, in which the primary current achieves its minimum value. At $411 \mathrm{kHz}$ occurs the series resonance. Figure 5 shows this situation, regarding the minimum input impedance. After the series resonance the input impedance presents an inductive behavior, as shown in Figure 6 . The leakage inductance can be estimated at frequencies higher than the series resonance. Table I summarizes the estimated parameters for the model of Figure 1.

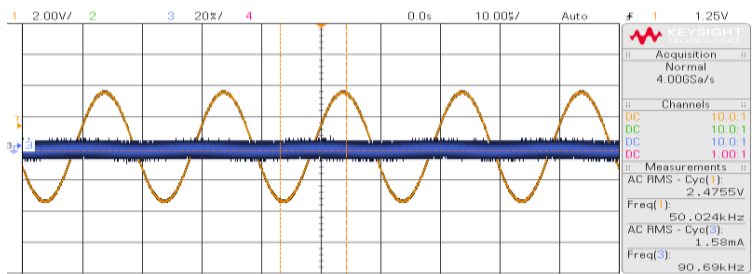

Fig. 4. Primary voltage (yellow) and current (blue) at the parallel resonance. 


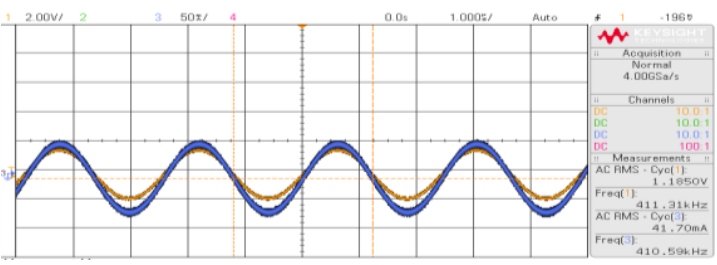

Fig. 5. Primary voltage (yellow) and current (blue) at the series resonance.

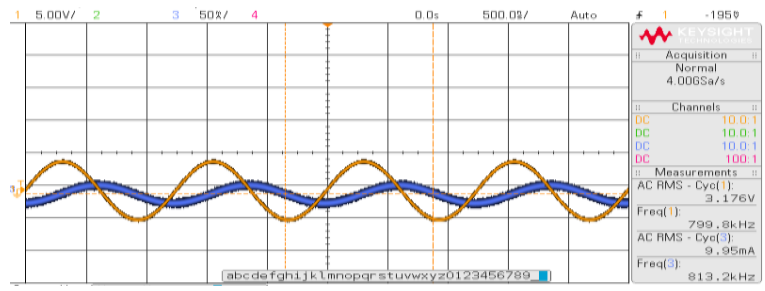

Fig. 6. Primary voltage (yellow) and current (blue) used to determine the leakage inductance.

TABLE I

\begin{tabular}{cc}
\hline Estimated Parameters for the Model of Figure 1 \\
\hline Parameter & Value \\
\hline$R_{d}$ & $0.329 \Omega$ \\
\hline$L_{d}$ & $63.5 \mu \mathrm{H}$ \\
\hline$C_{p}$ & $2.3 \mathrm{nF}$ \\
\hline$L_{m}$ & $5.64 \mathrm{mH}$ \\
\hline$R_{p}$ & $880 \Omega$ \\
\hline$f$ & $20 \mathrm{kHz}$ \\
\hline$f_{s}$ & $411 \mathrm{kHz}$ \\
\hline$f_{p}$ & $50 \mathrm{kHz}$ \\
\hline$n$ & 12 \\
\hline
\end{tabular}

The windings capacitance calculated by (1) and (2) are 1.8 $\mathrm{nF}$ and $2.3 \mathrm{nF}$, respectively. One of the reasons for the discrepancy is the secondary leakage inductance, that's not considered in the model [28] [33]. The considered value is $2.3 \mathrm{nF}$, since the critical situation is the excitation of the series resonance, that produces secondary overvoltage and primary overcurrent.

Figures 7 and 8 show the behavior of the input impedance and the voltage gain respectively for the open and nominal load, obtained from (3) and (4) with the parameters of Table I. The input impedance of Figure 7 could be directly obtained from an impedance analyzer, and so the transformer inductances and capacitances directly estimated from it [34], however the spectral analysis as it was performed reproduces the analyzer behavior with the use of simple devices, as signal generator and oscilloscope.

Figure 9 shows the waveforms for open load condition. The harmonics in the square input voltage nearest the series resonance are amplified and distort the secondary voltage, that achieves a peak more than two times the expected value. The magnetizing current is also affected by the resonance manifestation, causing the current stress shown in Figure 9.

The load has an important role for minimizing such behavior. As it appears in parallel with the magnetizing branch, it damps the series resonance. However, if the transformer operates without load, some procedure must be adopted in order to comply with the isolation capability.

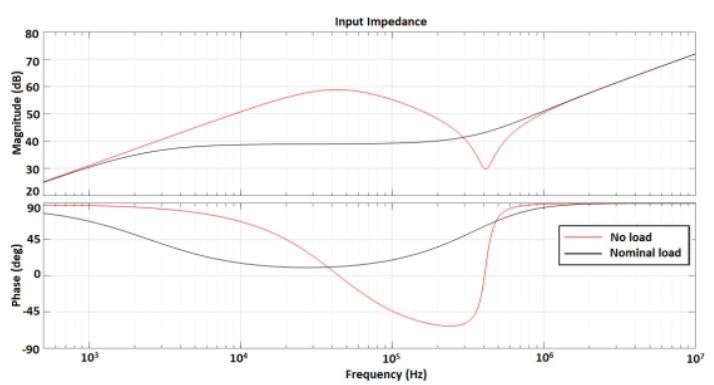

Fig. 7. Transformer's input impedance.

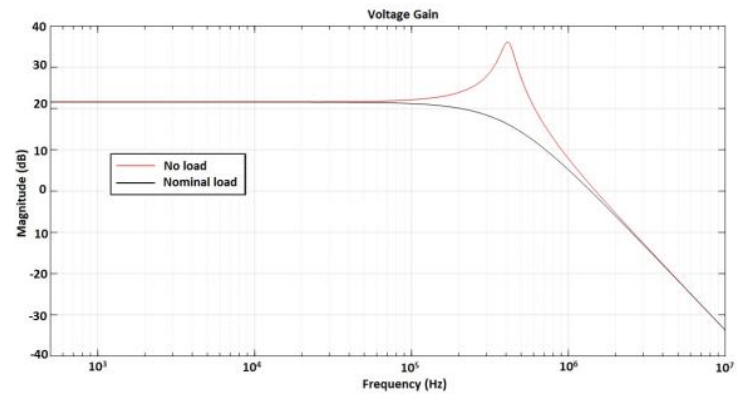

Fig. 8. Transformer's voltage gain.

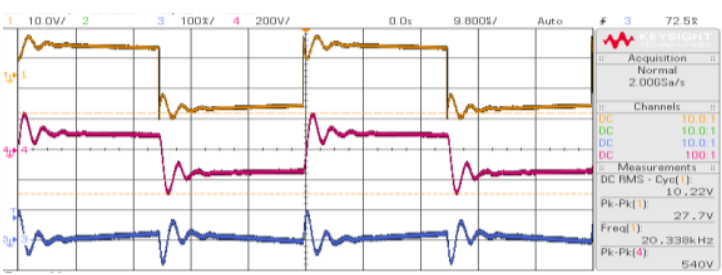

Fig. 9. Primary Voltage (yellow), Secondary Voltage (pink) and Primary current (blue), for the secondary open load condition.

\section{RESONANCE EXCITATION AND PROTECTION STRATEGIES}

Figure 10 shows a full bridge inverter feeding a HF HV transformer with a variable resistive load. The series capacitor $C_{\text {ext }}$ blocks DC components from the inverter, avoiding the transformer saturation [35]. The transformer parameters are the same of Table I, $R_{L}$ is a resistive variable load. The inverter parameters are listed in Table II.

Figure 11 shows the secondary voltage and the primary current for a PSIM simulation of Figure 10, with the parameters estimated by the spectral analysis. When the secondary is in open load condition, the primary current is the magnetizing current plus the resonant component, not damped by the load. The voltage peaks are more than two times the nominal voltage. This situation leads to the necessity of an overvoltage protection strategy, since the cost for increasing the isolation capability would be excessive.

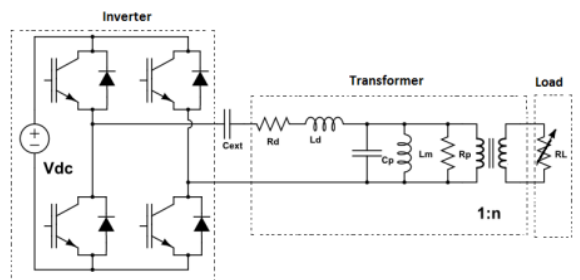

Fig. 10. Inverter feeding the transformer with a variable resistive load. 


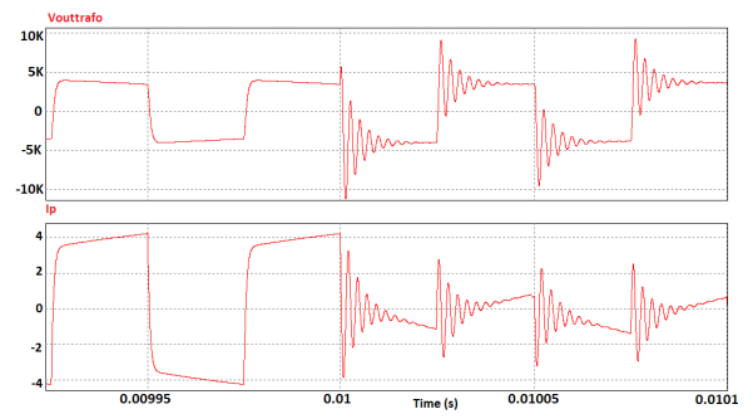

Fig. 11. Simulated waveforms of the transformer secondary voltage (top) and input current (bottom) for nominal power and open load conditions.

TABLE II

\begin{tabular}{cc}
\hline Inverter's Parameters of Figure 10 \\
\hline Parameter & Value \\
\hline$V_{d c}$ & $311 \mathrm{~V}$ \\
\hline$C_{\text {ext }}$ & $2 \mu \mathrm{F}$ \\
\hline Switching frequency & $20 \mathrm{kHz}$ \\
\hline
\end{tabular}

\section{A. Voltage Clamper}

Since the capacitance, $C_{p}$ is unreachable, it's impossible to, directly, limit its voltage. As such voltage is applied to the magnetizing inductance, it appears on the secondary side. To limit the voltage during open load operation, a voltage clamper [36] can be put at the secondary, as Figure 12 shows.

The clamper uses high voltage high frequency diodes, a high voltage capacitor $\left(C_{c l}\right)$ and enough resistive load $\left(R_{c l}\right)$. During normal operation, the capacitor charges with the nominal voltage. During the resonance, the clamper absorbs the energy associated with the $L_{d}-C_{p}$ tank and dissipates it on the resistor. There's a slightly increase peak voltage, but the $\mathrm{AC}$ output remains limited. Figure 13 shows the primary current and secondary voltage, for nominal and open load conditions with the clamper. The clamper resistance must be high to limit the losses but not so high in order to limit the overvoltage. Main drawbacks of this solution are the cost of HF HV components as well as the additional losses.

\section{B. External Inductor}

If the leakage inductance would be zero, the inverter would impose directly the voltage on the magnetizing branch, and no overvoltage would occur, even in the open load condition. However such ideal case is impossible, it can be approximate if the leakage inductance has a small value. In such situation an external inductor can be connected in series with the primary. Its value must be significantly higher (as around two to ten times) than the leakage inductance. The value can't be excessively high to not limit the primary current and, consequently, the power transfer.

The point between the inductor and the transformer is connected to the intermediary point of a diodes branch and connected to the inverter's DC link as Figure 14 shows [37].

The diodes branch operates as a clamper and limits the voltage on the primary to $+/-V_{d c}$. As the leakage inductance is small compared to the external inductor, the voltage at the magnetizing branch and at the output is limited, reducing the transformer high voltage peaks.
Figure 15 shows the output voltage limitation with the external inductor. The main drawback of this solution is the power factor reduction, due to higher series inductance. So, for a given output power, the input current will be higher than without the external inductor.

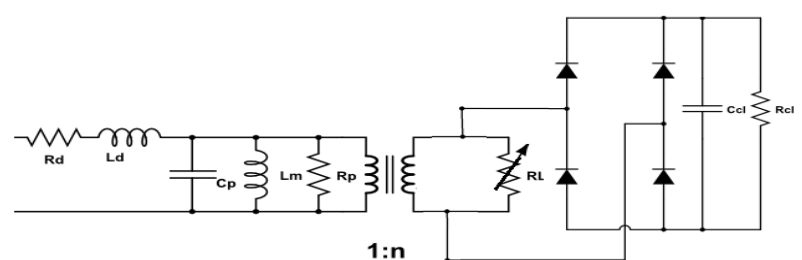

Fig. 12. System of Figure 11 with the voltage clamper at the secondary side.

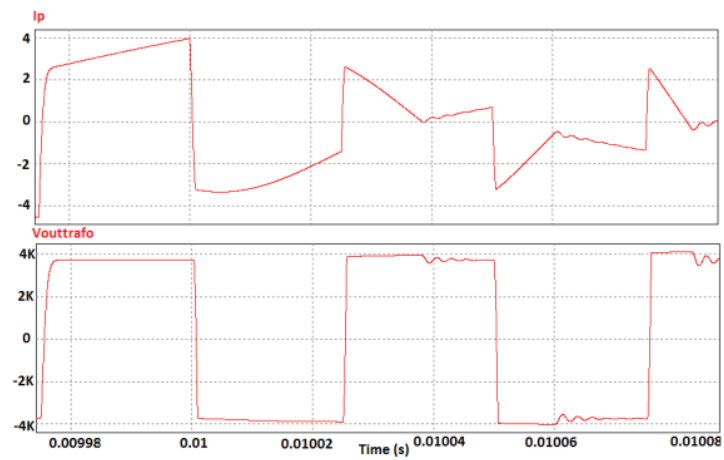

Fig. 13. Input current (top) and secondary voltage (bottom) with the clamper at open load.

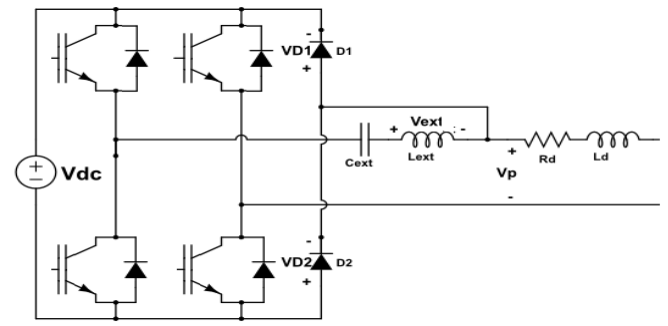

Fig. 14. External inductor strategy.
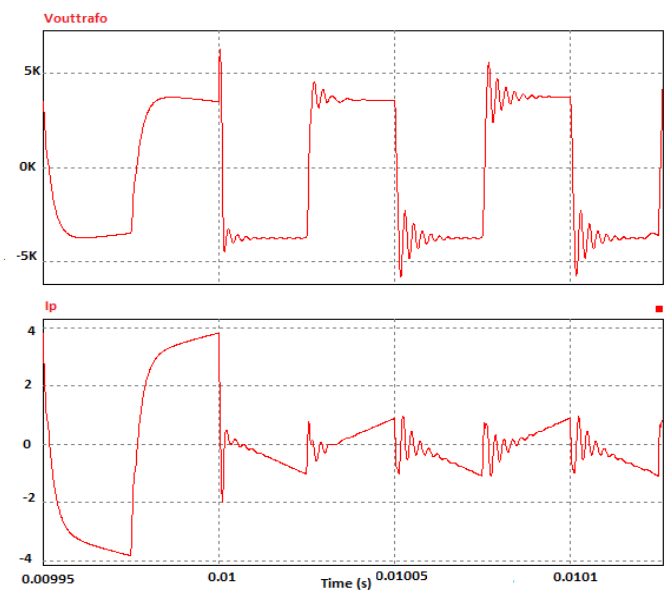

Fig. 15. Secondary voltage (top) and primary current (bottom) with the external inductor.

\section{Harmonic Reduction}

The series resonance won't be excited if the primary voltage doesn't have the respective harmonic. Without compromising the switching frequency, it's possible to 
produce a three-level waveform, including a zero-voltage step. The length of the zero interval allows eliminating one specific harmonic. For example, if the zero-voltage interval is $1 / 21$ of the period, the $21^{\text {st }}$ harmonic is cancelled.

Figure 16 shows the primary and secondary voltages and the primary current for this strategy, the $21^{\text {th }}$ harmonic was removed from the input signal, because the series resonance frequency is $411 \mathrm{kHz}$ and the operating frequency is $20 \mathrm{kHz}$.

As expected, the overvoltage has been reduced. The oscillation is the $19^{\text {th }}$ harmonic that remains in the applied rectangular voltage. The elimination of additional harmonics is possible, at the cost of increase the transistors switching frequency [38] [39] [40].

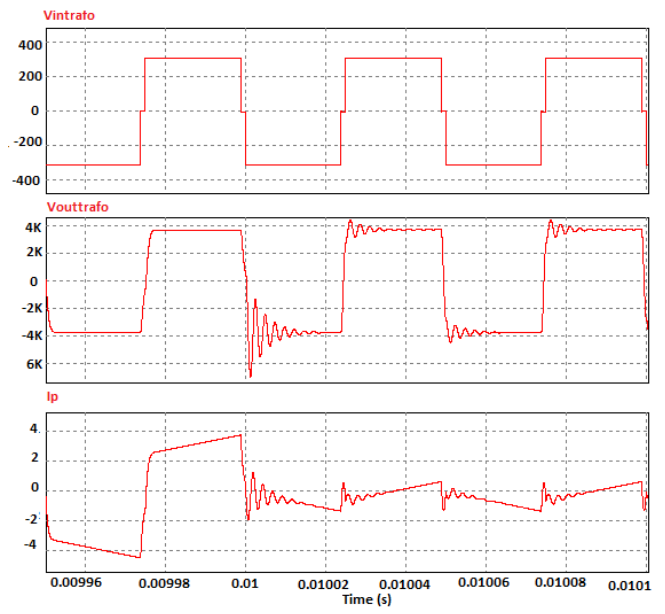

Fig. 16. From top to bottom: Primary voltage; secondary voltage and primary current for the harmonic control strategy.

\section{CRITERIA DESIGN FOR THE PROTECTION STRATEGIES}

\section{A. Voltage Clamper}

The magnetizing current with the series resonance manifestation is shown in Figure 17. The magnetizing current peak with the resonance manifestation is $I_{p}$. This value is achieved in a quarter of the wave-cycle at the resonant frequency. To determine $I_{p}$, the "natural" magnetizing current peak $I_{m}$ must be taken in consideration and its value subtracted from the total current in the resonant circuit. The value of $I_{m}$ can be estimated using the switching frequency, the DC link and $L_{m}$ values.

The resonant circuit may be regarded as a simple LC without losses. Its characteristic impedance is given by (5), the total current is given by (6) and $\mathrm{I}_{\mathrm{p}}$ is calculated by (7).

$$
\begin{gathered}
Z_{c}=\sqrt{\frac{L_{d}}{C_{p}}} \\
I_{c}=\frac{2 V_{d c}}{Z_{c}} \\
I_{p}=I_{c}-I_{m} .
\end{gathered}
$$

The total charge delivered by the "resonant current" during this time interval is calculated by (8) and determined by (9). Considering the transformer secondary can handle an overvoltage $\Delta V$, the clamper capacitor is given by (10).

$$
\begin{gathered}
Q_{s}=2 \int_{0}^{\frac{1}{2 f_{s}}} I_{p} \sin \left(2 \pi f_{s} t\right) d t \\
Q_{s}=\frac{2 I_{p}}{\pi f_{s}} \\
C_{c l}=\frac{2 I_{p}}{\pi f_{s} \Delta V} .
\end{gathered}
$$

The energy absorbed by $C_{c l}$ in a half period is given by (11) and must be dissipated on the clamper resistor. Considering the voltage on the resistor constant and equals to $V_{o}$, the power dissipate during the resonance is given by (12), and its value can be calculated by (13).

$$
\begin{gathered}
E_{s}=\frac{I_{p} \Delta V}{\pi f_{s}} \\
P_{R_{c l}}=\frac{E_{s}}{T / 2} \\
R_{c l}=\frac{\left(V_{0}\right)^{2} \pi f_{s}}{2 I_{p} \Delta V f} .
\end{gathered}
$$

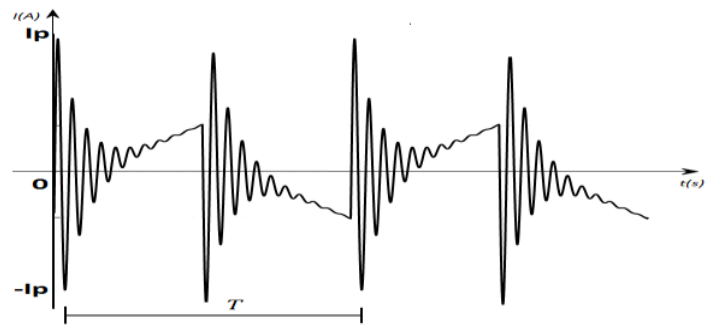

Fig. 17. Magnetizing current with the series resonance manifestation.

For the $1 \mathrm{kVA}$ ferrite transformer, the output voltage at normal operation is $3.8 \mathrm{kV}$. The magnetizing current is 0.69 A, the characteristic impedance $164 \Omega$ and the total resonant peak current $3.79 \mathrm{~A}$. The $\mathrm{I}_{\mathrm{p}}$ value is $3.10 \mathrm{~A}$. The clamper parameters, considering an overvoltage of $200 \mathrm{~V}$ are showed in Table III.

TABLE III

\begin{tabular}{cc}
\hline Determined Parameters for the High Voltage Clamper \\
\hline Parameter & Value \\
\hline$C_{c l}$ & $24 \mathrm{nF}$ \\
\hline$R_{c l}$ & $748.29 \mathrm{k} \Omega$ \\
\hline
\end{tabular}

\section{B. External Inductor}

Figure 18 shows the waveforms for the external inductor and the primary voltage at nominal conditions, as well as the inverter output voltage.

During the positive half-cycle, the inverter's output is $V_{d c}$. The external inductor is initially uncharged, behaving as an open circuit with a voltage drop higher than $V_{d c}$. The primary voltage is the difference between the inverter and inductor 
voltages, so it is 0 . The voltage on $\mathrm{D}_{1}$ and $\mathrm{D}_{2}$ are $-V_{d c}$ and 0 respectively, as seen in Figure 18. The higher initial voltage on the external inductor is due to $C_{e x t}$ effect.

As the inductor charges, its voltage tends to zero and the primary increases gradually to $V_{d c}$. The voltages on $\mathrm{D}_{1}$ and $\mathrm{D}_{2}$ tend to 0 and $-V_{d c}$ respectively. When the semi-cycle changes, the behavior is similar, but the voltage values are opposite, as seen in Figures 18 and 19. The primary, inductor and diode currents are also shown in Figures 20 and 21, for the open load condition. There's a slight difference between the inductor and primary currents, because of the current circulation trough the diodes. The diodes polarization depends on the voltage at the point between the external inductor and the primary.

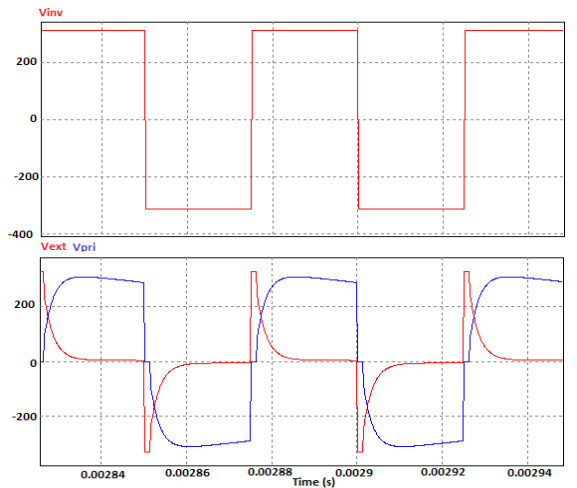

Fig. 18. From top to bottom: Inverter output voltage; Primary and external inductor voltages, at nominal conditions.

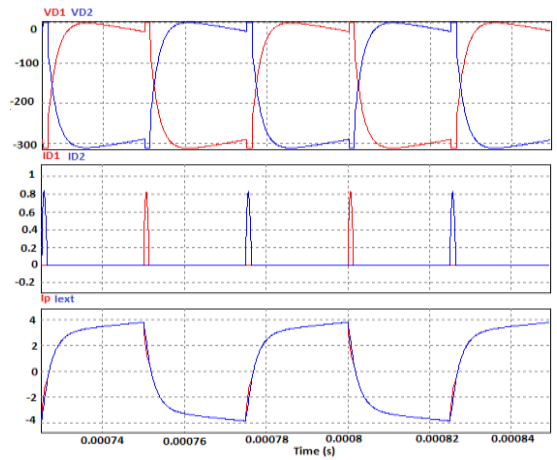

Fig. 19. From top to bottom: Diodes voltages; Diodes current; Primary and external inductor currents, for the external inductor strategy at nominal conditions.

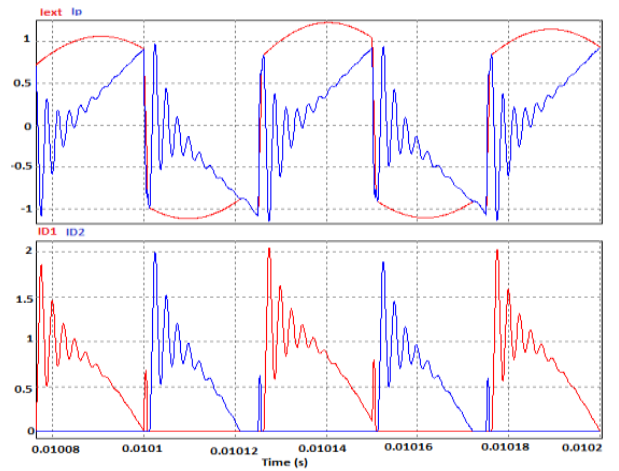

Fig. 20. Waveforms for the external inductor strategy at open load condition. From top to bottom: Primary and inductor currents; Diode currents.

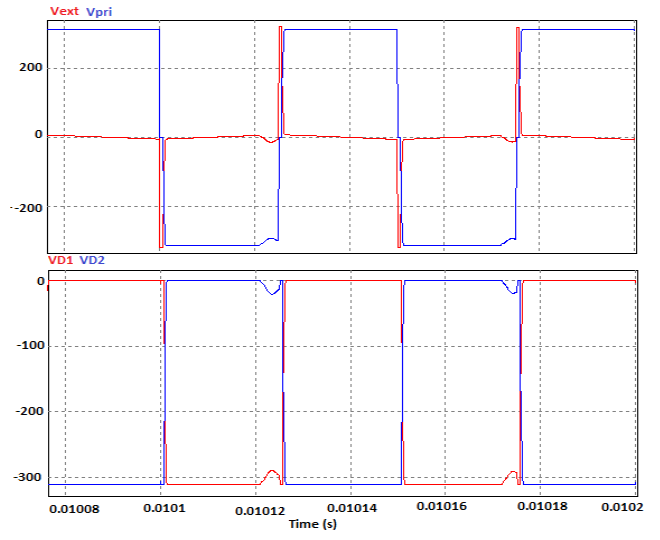

Fig. 21. Voltages at open load condition. From top to bottom: Primary and external inductor; Diodes.

If the leakage inductance is high, this solution can't be applied. Table IV shows the output power obtained from simulations of the external inductor strategy with nominal load at the secondary and the respective voltage peak in the open load condition. It can be seen that higher the external inductor, lower the open load voltage peak, but lower the power delivered and the output RMS voltage. The results confirm that the best system performance (more overvoltage and less output power reduction) is when the inductor is nearly between around two to ten times the leakage inductance.

TABLE IV

\begin{tabular}{cccc}
\hline \multicolumn{4}{c}{ Power and Voltage Variation With the External Inductor } \\
\hline $\begin{array}{c}\text { External } \\
\text { Inductor }\end{array}$ & $\begin{array}{c}\text { Outut Voltage } \\
\text { rms value }\end{array}$ & Output Power & $\begin{array}{c}\text { Secondary open } \\
\text { voltage peak }\end{array}$ \\
\hline $0 \mu \mathrm{H}$ & $3.68 \mathrm{kV}$ & $944 \mathrm{~W}$ & $9.2 \mathrm{kV}$ \\
\hline $100 \mu \mathrm{H}$ & $3.46 \mathrm{kV}$ & $834 \mathrm{~W}$ & $6.3 \mathrm{kV}$ \\
\hline $150 \mu \mathrm{H}$ & $3.34 \mathrm{kV}$ & $778 \mathrm{~W}$ & $5.8 \mathrm{kV}$ \\
\hline $200 \mu \mathrm{H}$ & $3.21 \mathrm{kV}$ & $720 \mathrm{~W}$ & $5.2 \mathrm{kV}$ \\
\hline $300 \mu \mathrm{H}$ & $2.96 \mathrm{kV}$ & $610 \mathrm{~W}$ & $4.5 \mathrm{kV}$ \\
\hline $600 \mu \mathrm{H}$ & $2.22 \mathrm{kV}$ & $350 \mathrm{~W}$ & $3.8 \mathrm{kV}$ \\
\hline
\end{tabular}

\section{Harmonic Reduction}

The waveform is shown in Figure 22, the half-wave and odd symmetry result the Fourier series given by (14). The Fourier coefficients are given by (15), with $t_{1}$ being the zero interval per half-period and determined by (16). By putting (16) in (15), the expression in (17) is derived. Not only $b_{N}$, but all the harmonics multiple of $N$ are eliminated.

A drawback of this solution is the reduction of the applied RMS voltage, which impacts the power transfer. For the 1 $\mathrm{kVA}$ transformer, the output power is $899 \mathrm{~W}$. When this strategy is used, it's necessary to redesign the transformer for the specific input voltage waveform.

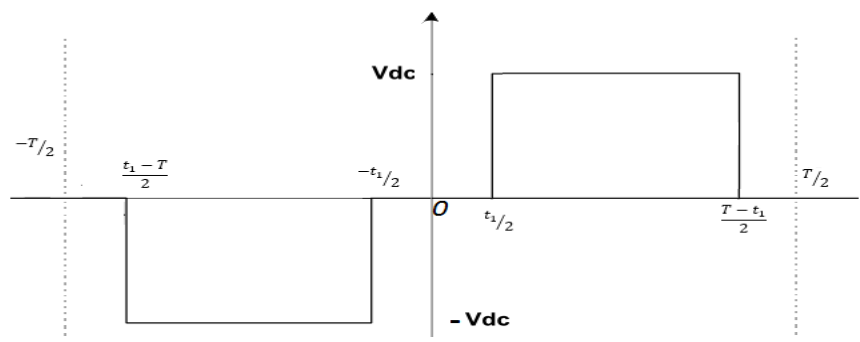

Fig. 22. Square wave with zero-step. 


$$
\begin{gathered}
f(t)=\sum_{n=1}^{\infty} b_{n} \sin \frac{2 \pi n t}{T} \\
b_{n}=\frac{4 V_{d c}}{\pi n} \cos \frac{\pi n t_{1}}{T} \\
t_{1}=\frac{T}{2 N} \\
b_{n}=\frac{4 V_{d c}}{\pi n} \cos \frac{\pi n}{2 N} .
\end{gathered}
$$

\section{EXPERIMENTAL RESULTS}

Figure 23 shows the prototype, where it's seen the HF HV transformer, the voltage inverter, the HV clamper and the measurement setup. A high voltage probe Tektronix P 6015A is used to measure the secondary voltage. The probe has a capacitance of $3 \mathrm{pF}$, that changes the resonance frequency to nearly $380 \mathrm{kHz}$, reducing the tank circuit impedance and increasing the resonant current. So, there will be some mismatches between simulations and experimental results.

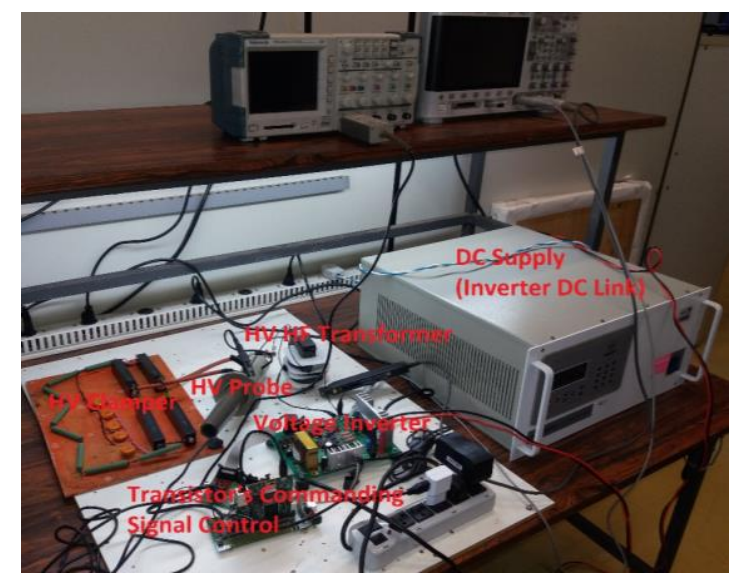

Fig. 23. Experimental setup for the practical measurements of the overvoltage protection strategies.

Figure 24 shows the primary waveforms for a resistive load of $12.5 \mathrm{k} \Omega$ and Figure 25 the respective secondary voltage. The input power was almost $1.1 \mathrm{~kW}$.

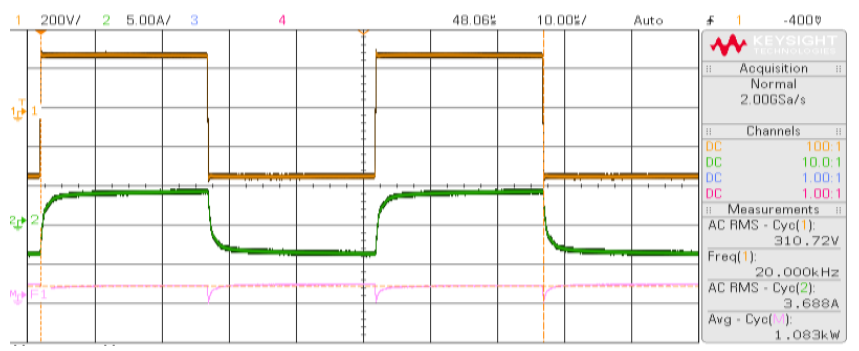

Fig. 24. Primary voltage (yellow), primary current (green) and input power (pink) for a resistive load of $12.5 \mathrm{k} \Omega$.

Figure 26 shows the primary waveforms for a load of 75 $\mathrm{k} \Omega$ and Figure 27 the corresponding secondary voltage. The secondary approximates the open load condition when the load value increases, reducing the damping and increasing primary current and secondary voltage peaks. In this case, the voltage peak is already two times the value of Figure 25.

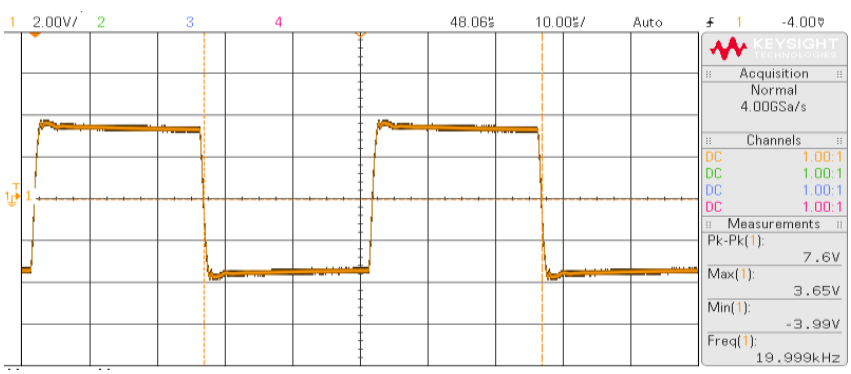

Fig. 25. Secondary voltage corresponding to the primary waveforms of Figure 24. Vertical scale 1:1000.

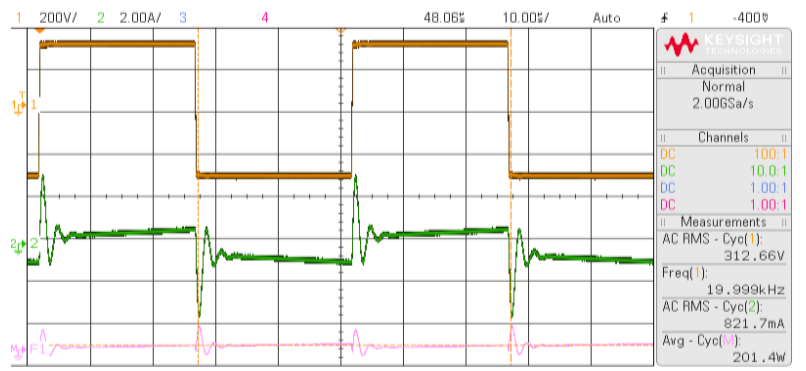

Fig. 26. Primary voltage (yellow), primary current (green) and input power (pink) for a resistive load of $75 \mathrm{k} \Omega$.

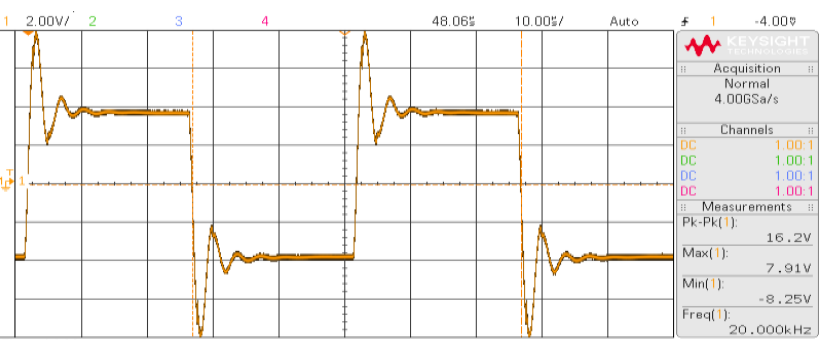

Fig. 27. Secondary voltage for the primary waveforms of Figure 26. Vertical scale 1:1000.

\section{A. Secondary Clamper}

The primary waveforms for the HV clamper strategy at the open load condition are showed in Figure 28 and the corresponding secondary voltage in Figure 29, For the clamper capacitor prototyping it was used a combination of five capacitors of $4.7 \mathrm{nF}$ in parallel and, for the resistor, eight of $100 \mathrm{k} \Omega$ in series. The secondary voltage peak is nearly 4.5 $\mathrm{kV}$ and the primary current peak almost $5 \mathrm{~A}$. The waveforms show the effectiveness of this strategy. The input power was $56.2 \mathrm{~W}, 5.62 \%$ of the nominal power.

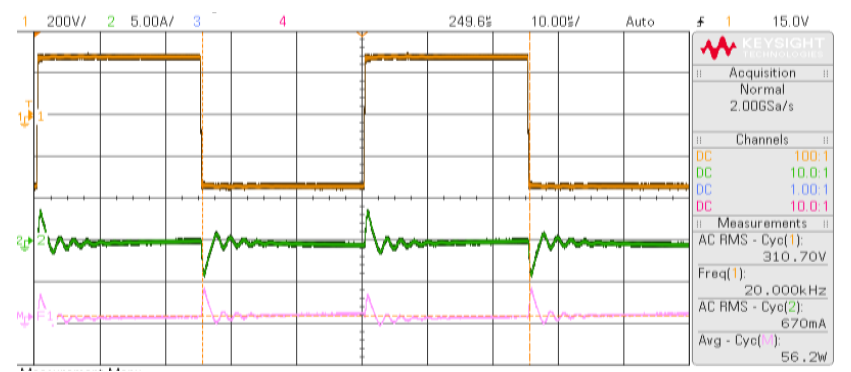

Fig. 28. Primary waveforms for the voltage clamper strategy. From top to bottom: Primary voltage, Primary current and input power. 


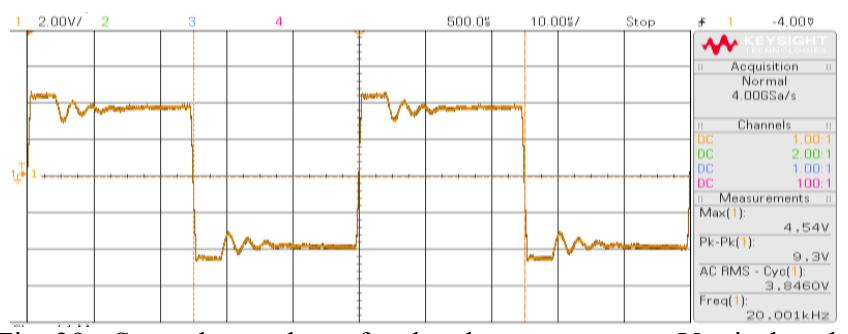

Fig. 29. Secondary voltage for the clamper strategy. Vertical scale $1: 1000$.

\section{B. External Inductor}

Figure 30 shows the primary waveforms for the external inductor strategy at the open load condition, and Figure 31 the corresponding secondary voltage, the external inductor value is $150 \mu \mathrm{H}$. The secondary voltage peak was $4.5 \mathrm{kV}$ and the primary current peak less than $2 \mathrm{~A}$. The input power was $10.2 \mathrm{~W}$.

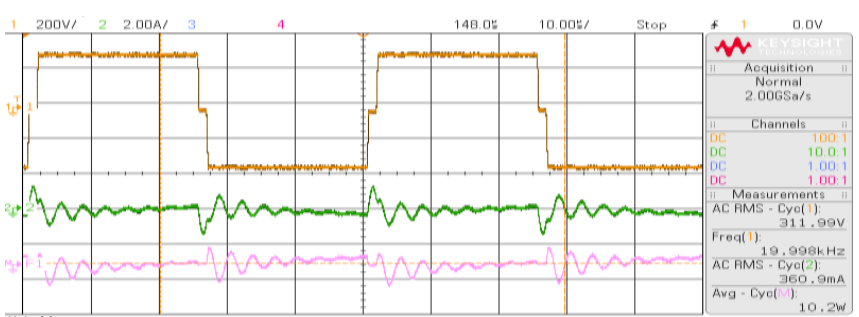

Fig. 30. Primary voltage (yellow), Primary current (green) and input power (pink) for the external inductor strategy, with the secondary in the open load.

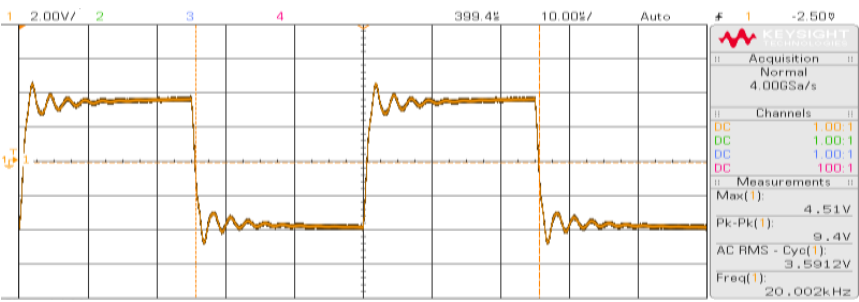

Fig. 31. Secondary Voltage in the open load condition for the external inductor strategy. Vertical scale 1:1000.

\section{Harmonic Control}

Figure 32 shows the primary waveforms for the selective harmonic elimination and Figure 33 the corresponding secondary voltage for the open load condition. As the primary voltage period is $50 \mu \mathrm{s}$ and the harmonic to be eliminated is the $21^{\text {st }}$, the value of $t_{1}$ determined by (16) is $1.19 \mu \mathrm{s}$. The secondary voltage peak was about $4.3 \mathrm{kV}$ and the primary current peak almost the same as in the external inductor strategy. The input power was less than $20 \mathrm{~W}$. The waveforms show the effectiveness of this strategy.

Table V summaries some important information about the protection strategy. The external inductor and voltage clamper have similar performance in terms of overvoltage reduction. The external inductor has less power loss, but can only be applied if the leakage inductance has a small value, as the voltage clamper does not have this project restriction.

The harmonic elimination had the best overvoltage reduction, but it can't be applied if the series resonance happens in harmonics too far from the switching frequency.

The harmonic elimination and external inductor reduce the power transfer, once they decrease the RMS value of the primary voltage, so besides the overvoltage protection, the application efficiency necessity must be taken in consideration.

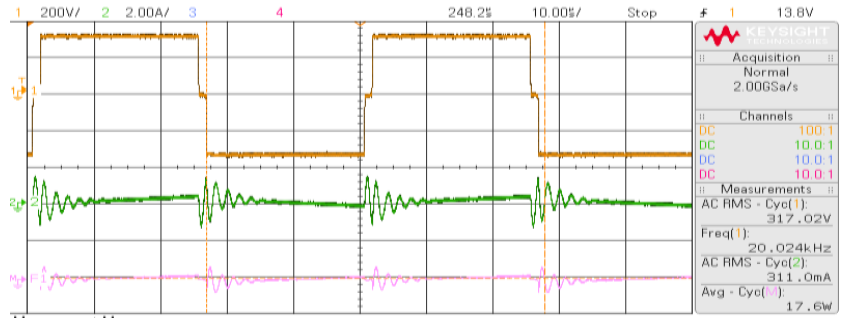

Fig. 32. Primary waveforms for the selective harmonic elimination.

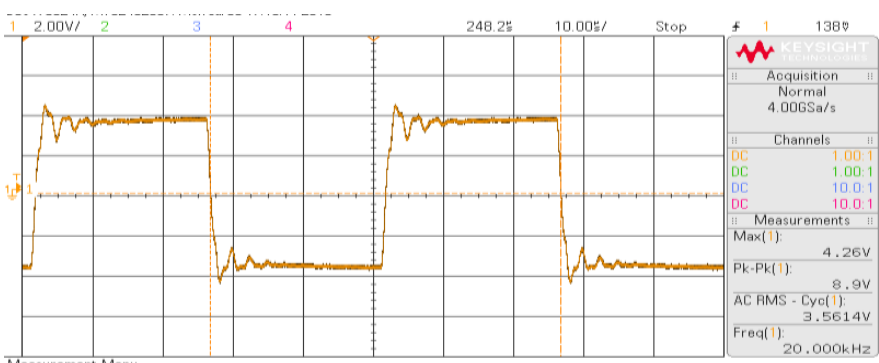

Fig. 33. Secondary voltage corresponding to the selective harmonic elimination strategy. Vertical scale 1:1000.

TABLE V

\begin{tabular}{ccccc}
\hline \multicolumn{5}{c}{ Comparison Among the Overvoltage Protection } \\
Strategies for Open Load
\end{tabular}

\section{CONCLUSIONS}

In this paper the nature and problems of overvoltage in the open circuit operation of High Voltage High Frequency transformers were explored and different protection strategies to limit the voltage stress were proposed, depending on the transformer parasitic elements values, mainly the leakage inductance and the windings capacitance. The strategies apply in situations in which the load varies instantaneously, asking for an overvoltage protection implemented in hardware, since no closed loop control would be so fast in order to protect the devices.

The strategies were simulated and validated by experimental results. The operation of each strategy was analyzed, and design criteria were established.

The high voltage probe capacitance impacts the measurements, however it doesn't affect the comparison, since all the results were acquired at the same conditions. The probe capacitance probably is one of the reasons for the damping differences between the measured and simulated 
waveforms. Another reason could be system losses that were not modeled. For sure, the lumped parameters model is not able to perfectly represent the internal behavior of the transformer, although it represents with a good precision the power transferring phenomena.

The external inductor is the simplest strategy, but it's only indicated when the leakage inductance value is small. The selective harmonic elimination is more effective if the series resonance happens in a low frequency range. The HV clamper has the disadvantage of HF HV components necessity and can be expensive in high power applications.

\section{ACKNOWLEDGEMENTS}

The authors acknowledge Zasso Brazil for financially supporting this research.

\section{REFERENCES}

[1] L. A. F. d. Oliveira, Study of High Frequency Transformer Models (in Portuguese), Belo Horizonte, MG: UFMG, June 2011.

[2] C. W. T. McLyman, Transformer and Inductor Design Handbook, 3 ed., New York: Marcel Dekker Inc, 2004.

[3] R. Petrov, "Optimum Design of High-Power, HighFrequency Transformer", in IEEE Transactions on Power Electronics, vol. 11, no. 1, p. 33-42, January 1996.

[4] A. R. A. Razak and S. Tajb, "Design considerations of a high frequency power transformer," in National Power Engineering Conference (PECon), Bangi, December 2003.

[5] J. A. Pomilio, O. Bet and M. P. Vieira, "High-Voltage Resonant Converter with Extreme Load Variation: Design, Criteria and Applications", in International Journal of Electrical, Computer, Electronics and Communication Engineering, vol. 8, no. 12, p. 17641769, 2014.

[6] H. Y. Lu, J. G. Zhu, V. S. Ramsden and S. Y. R. Hui, "Measurement and Modeling of Stray Capacitances in High Frequency Transformers", in IEEE Power Electronics Specialists Conference, p. 763-768, 1 July 1999.

[7] H. Y. Lu, J. G. Zhu and S. Y. R. Hui, "Experimental Determination of Stray Capacitances in High Frequency Transformers", in IEEE Trans. on Power Electronics, vol. 18, no. 5, p. 1105-1112, September 2003.

[8] G. S. Sperandio and J. A. Pomilio, "High-efficiency, high-frequency inverter for silent discharge load", in Brazilian Power Electronics Conference, Blumenau, October 2007.

[9] D. Tardivo and J. A. Pomilio, "Resonant High-voltage supply for multiple paralleled loads with parameter equalization", in Brazilian Power Electronics Conference, Natal, September 2011.

[10] W. Shen, Design of High-Density Transformers for High-Frequency High-Power Converters, Blacksburg, Vrginia: Virginia Polytechnic Institute State University, July 2006.
[11] W. Shen, F. Wang, D. Boroyevich and C. W. Tipton, "High power density nanocrystalline core transformer design for resonant converter systems", in 40th Industry Applications Conf., vol. 3, p. 2216-2222, October 2005.

[12] M. A. Perez, C. Blanco, M. Rico and F. Linera, "A New Topology for High Voltage High Frequency Transformers", in IEEE Applied Power Electronics Conference and Exposition, vol. 2, p. 554-559, March 1995.

[13] M. Biberoglu, T. N. Gücin and B. Fincan, "Analyzing the influences of high frequency transformeres utilized in parrallel resonant converters", in IEEE International Conference on Renewable Energy Research and Applications, p. 983-988, November 2016.

[14] A. Atalla, M. Agamy, M. Dame, L. Hao, G. Mandrisiak and Y. Pan, "Advancements in high power high frequency transformer design for resonant converter circuits", in IEEE Energy Conversion Congress and Exposition, p. 1-8, September 2016.

[15] O. Patterson and D. Divan, "Pseudo-Resonant Converter Technologies", in IEEE 18th Power Electronics Specialists Conference, Blacksburg, June 1987.

[16] A. Mizuno, A. Nagura, T. Miyamoto, A. Chakrabarti, T. Sato, K. Kimura, T. Kimura and M. Kobayashi, "A portable weed control device using high frequency AC voltage", in IEEE Industry Applications Conference, vol. 3, p. 2000-2003, October 1993.

[17] S. Mao, J. Popovic and J. A. Ferreira, "An Investigation into High Frequency High Voltage Planar Transformer for High Voltage Generator Applications", in IEEE International Conference on Integrated Power Electronics Systems, p. 1-6, March 2016.

[18] Y. A. Wang and D. M. Xiao, "Prototype design for a high-voltage high-frequency rectifier transformer power use", in IET Power Electronics, vol. 4, no. 6, p. 615623, July 2011.

[19] J. Baizan, A. Navarro-Crespin, R. Casanueva, F. J. Azcondo, C. Brafias and F. J. Diaz, "Converter with four quadrant switches for EDM Applications", in IEEE Industry Applications Annual Meeting, October 2013.

[20] R. Casanueva, C. Brañas, F. J. Azcondo and S. Bracho, "Resonant converters: properties and applications for variable loads", in 31st Annual Conference of IEEE Industrial Electronics Society, November 2005.

[21] S. de Andrade Coutinho Filho, J. A. Pomilio, B. Valverde and D. Teruo Mendes de Souza, "Weed Inactivation Device". Patent WO/2019/102243, 2019.

[22] D. T. M. Souza, B. Valverde and J. A. Pomilio, "Overvoltage protection procedures for high frequency high voltage transformers", in 14th Brazilian Power Electronics Conference (COBEP), Juíz de Fora, November 2017.

[23] F. D. Leon and A. Semlyen, "Efficient calculation of elementary parameters of transformers", in IEEE Transactions on Power Delivery, vol. 7, no. 1, p. 376383, January 1992.

[24] M. M. Kane and S. V. Kulkarni, "MTL-Based analysis to distinguish high-frequency behavior of interleaved 
windings in power transformers", in IEEE Trans. on Power Delivery, vol. 28, no. 4, p. 2291-2299, July 2013.

[25] H. Y. Lu, J. G. Zhu and S. Y. R.Hui, "Experimental determination of stray capacitances in high-frequency transformers", in IEEE Transactions on Power Electronics, vol. 18, no. 5, p. 1105-1112, August 2003.

[26] J. Bielar and J. W. Kolar, "Using transformer parasitics for resonant converters-a review of the stray capacitance of transformers", in IEEE 40th Industry Applications Conference, vol. 3, p. 1868-1875, October 2005.

[27] B. Cogitore, J. P. Keradec and J. Barbaroux, "The twowinding transformer: experimental method to obtain a wide frequency equivalent circuit", in IEEE Transactions on Instrumentation and Measurement, vol. 43, no. 2, p. 364-371, April 1994.

[28] D. T. M. Souza and J. A. Pomilio, "Comparison between lumped models for high-voltage highfrequency transformers", in 13th IEEE International Conference on Industry Applications (INDUSCON), São Paulo, November 2018.

[29] P. Mayer, P. Germano and Y. Perriard, "FEM modeling of skin and proximity effects for coreless transformers", in IEEE 15th International Conference on Electrical Machines and Systems (ICEMS), p. 1-6, October 2012.

[30] A. Roßkopf, E. Bär and C. Joffe, "Influence of Inner Skin and proximity Effects on Conduction Litz Wires", in IEEE Transactions on Power Electronics, vol. 29, no. 10, p. 5454-5461, October 2014.

[31] C. R. Sullivan and R. Y. Zhang, "Simplified Design Method for Litz Wire", in IEEE Applied Power Electronics Conference and Exposition, p. 2667-2674, April 2014.

[32] S. A. D. Contreras, Study of the Application of Intercellular Transformers in Voltage Inverters (in Portuguese), Belo Horizonte, MG: UFMG, July 2014.

[33] N. Shafiei, M. Pahlevaninezhad, H. Farzanehfard, A. Bakhshai and P. Jain, "Analysis of a Fifth-Order Resonant Converter for High-Voltage DC Power Supplies", in IEEE Transactions on Power Electronics, Vol.28, N.1, p. 85-100, January 2013.

[34] G. L. Piazza, R. L. Alves, C. H. I. Font and I. Barbi, "Resonant circuit model and design for a high frequency high voltage switched-mode power supply", in 10th Brazilian Power Electronics Conference (COBEP), Bonito, September 2009.

[35] J. P. Bonaldo, Power Converter Feeding Ozone Generation Cells (in Portuguese), Campinas, SP: Unicamp, April 2010.

[36] J. Rocabert, M. M. Dumenjo, J. Bordonau and J. A. B. Jimenez, "A regenerative active clamp circuit for $\mathrm{DC} / \mathrm{AC}$ converters with high-frequency isolation in photovoltaic systems", in IEEE 35th Annual Power Electronics Specialists Conference, vol. 3, p. 20822088, June 2004.

[37] F. Tsai and F. C. Lee, "A complete dc characterization of a constant-frequency, clamped-mode, series-resonant converter", in IEEE 19th Power Electronics Specialists Conference, Kyoto, April 1988.
[38] S. Bhadra, D. Grogory and H. Pitangia, "An analytical solution of switching angles for Selective Harmonic Elimination (SHE) in a cascaded seven level inverter", in IEEE 2nd Southern Power Electronics Conference, Auckland, December 2016.

[39] M. S. A. Dahidah, G. Konstantinou and V. G. Agelidis, "A Review of Multilevel Selective Harmonic Elimination PWM: Formulations, Solving Algorithms, Implementation and Applications", in IEEE Transactions on Power Electronics, vol. 30, no. 8, p. 4091-4106, August 2015.

[40] N. V. Kumar, V. K. Chinnaiyan, M. Pradish and M. S. Divekar, "Selective harmonic elimination: An comparative analysis for seven level inverter", in IEEE Students' Technology Symposium (TechSym), Kharagpur, October 2016.

[41] C. K. Alexander and M. N. O. Sadiku, Fundamentals of Electric Circuits, 5th ed., New York: McGraw-Hill, 2013.

[42] E. M. Stein and R. Shakarchi, Princeton Lectures in Analysis I Fourier Analysis An introduction, New Jersey: Princeton University Press, 2002.

\section{BIOGRAPHIES}

Diego Teruo Mendes de Souza was born in Ferraz de Vasconcelos, SP, Brazil, on January 9th, 1992. He received the B.S. in Electrical Engineering from the Federal University of Viçosa (UFV), Viçosa, MG, Brazil in 2016 and the M.S. from University of Campinas, Brazil, in 2018. He is currently professor at the Faculty of Americana and R\&D Engineer at Zasso Brazil. His research fields of interest include: Power Electronics, Electromagnetism, Control Engineering, Power Grid.

Bruno Valverde was born in Jundiaí, Brazil, in 1990. He received the B.S. degree in Electrical Engineering from the Federal University of São Carlos (UFSCar), São Carlos, Brazil, in 2016 and the M.S. from University of Campinas, Brazil, in 2019. He is currently R\&D Engineer at Zasso Brazil. His research fields of interest include Power electronics, More Electric Aircraft systems, high voltage resonant sources and Microgrids.

José Antenor Pomilio (M'92-SM'02) was born in Jundiaí, Brazil, in 1960. He received the B.S., M.S., and Ph.D. degrees in electrical engineering from the University of Campinas, Brazil, in 1983, 1986, and 1991, respectively. From 1988 to 1991, he was the Head of the Power Electronics Group, Brazilian Synchrotron Light Laboratory. He was a Visiting Professor with the University of Padova, in 1993 and 2015 and with the Third University of Rome, in 2003, both in Italy. He is a Professor with the School of Electrical and Computer Engineering, University of Campinas, where he has been teaching since 1984. Dr. Pomilio was the President of the Brazilian Power Electronics Society in 2000-2002, member of the Administrative Committee of the IEEE Power Electronics Society in 19972002, and Associated Editor of the IEEE Transaction on Power Electronics in 2003-2018. 